utilized facility level data from the Medicare Cost Reports from 2000 to 2013. The sample size will be approximately 15,600 facilities per year. Hospital-based skilled nursing facilities, government facilities and nursing homes that receive no Medicare will be excluded from the study.

The validated Altman's Z-score model for nursing homes can serve as a tool for policymakers to identify nursing homes under financial distress. This can facilitate interventions targeting nursing homes that are at risk of closure.

\section{FROM THE CFO TO THE BEDSIDE: AN EXAMINATION OF NURSING HOME FINANCIAL DISTRESS ON QUALITY}

J. Lord, R. Weech-Maldonado, G. Davlyatov, University of Alabama at Birmingham, Birmingham, Alabama

From 2000 through 2013, there have been 1,223 nursing home closures. Nursing home closures have been shown to have a negative impact on the displaced resident's health. Displaced nursing home residents often face significant detrimental health effects, such as, a decrease in social engagement and with activities of daily living. Nursing homes that typically close do so because of financial difficulties.

This paper will examine the quality of care delivered in nursing homes under financial distress. This study will use 2000-2013 data from the Medicare Cost Reports, the Online Survey Certification of Automated Records (OSCAR), Certification and Survey Provider Enhanced Reports (CASPER), Long-Term Care (LTC) Focus, and the Area Resource File. The sample size will be approximately 15,600 facilities per year. The dependent variables consist of quality variables that include RN, LPN, and CNA staffing ratios, residents with catheters, restraints, pressure ulcers, bowel incontinence, bladder incontinence, hospitalizations, re-hospitalizations, and facility quality of care deficiencies. The independent variable will consist of a dichotomous variable identifying where a nursing home is in financial distress as calculated by the validated Altman Z-score. Control variables include for-profit status, size, acuity index, and market competition (Herfindahl Index). Data are analyzed using fixed effects regression and lagged independent variables.

If financial distress is correlated with inferior resident quality care, this should illuminate some reasons for disparities in the delivery of care of long-term care. Understanding how organizational performance is correlated with resident care quality has the potential to provide insights on how to address and improve patient care delivery.

\section{THE 2015 ELDER ECONOMIC SECURITY STANDARD INDEX: GEOGRAPHIC AND DEMOGRAPHIC ASPECTS}

Y. Li ${ }^{1}$, P. Xu ${ }^{1}$, J.E. Mutchler ${ }^{1}$, J. Lyu ${ }^{3}$, 1. Gerontology, UMass Boston, Boston, Massachusetts, 3. Institute of Aging, Hallym University, Chuncheon, Korea (the Republic of)

The Elder Economic Security Standard Index (Index) offers a cost of living standard for independent, community-dwelling singles and couples aged 65 and older, calculated for every county in the United States. The Index includes local cost of housing, food, transportation, healthcare, and other expenses. Annual costs of living are calculated under three housing scenarios: homeowners with a mortgage, homeowners without a mortgage, and renters. Across these scenarios, the Index shows that cost of living increased 1\% - 7\% for seniors from 2011 to 2015. National summaries indicate that for singles in good health, annual Index values range from $\$ 19,872$ to $\$ 30,516$; for couples, they range from $\$ 30,288$ to $\$ 40,932$. Single homeowners in good health and without a mortgage have the lowest cost, whereas couple homeowners in poor health and with a mortgage have the highest cost of living. We illustrate spatial variation in cost of living for older adults using maps and spatial analysis techniques. Further analysis highlights gaps between cost of living and the typical Social Security benefit; these gaps also differ substantially across geographic areas. Locations in which the cost of living for seniors has increased most markedly between 2011 and 2015 are identified. We also identify gender, race, and age segments within the older population that are most substantially impacted by spatial inequality in cost of living for older adults. Resources for adults who are older, female, or of a racial or ethnic minority group are more likely to fall below the Index value.

\section{EXAMINING ORGANIZATIONAL AND MARKET FACTORS ASSOCIATED WITH NURSING HOME FINANCIAL DISTRESS}

J. Lord, R. Weech-Maldonado, G. Davlyatov, University of Alabama at Birmingham, Birmingham, Alabama

From 2000 through 2013, there have been 1,223 nursing home closures. Nursing home closures have a negative effect on the health of the displaced resident as well as adverse societal implications (i.e. lost jobs and reduced access). This paper will focus on the market and organizational contextual factors associated with nursing homes that are under financial distress.

This study will use 2000-2014 data from the Medicare Cost Reports, the Online Survey Certification of Automated Records (OSCAR), Certification and Survey Provider Enhanced Reports (CASPER), Long-Term Care (LTC) Focus, and the Area Resource File. Organizational factors such as chain affiliation, for-profit status, staffing, occupancy rates, acuity index, payer-mix, age of facility, and other related organizational factors will be explored. The market forces like a county's level unemployment, per capita income, percent of minority population, education levels, community size (rural vs. metropolitan), managed care penetration, Medicaid reimbursements and level of competition will also be explored. The independent variable will consist of nursing homes in financial distress as calculated by the validated Altman Z-score. Using regression analysis with state and year fixed effects, the study will examine the impact of these factors on nursing home financial distress.

Unfortunately, nursing home closures do not impact all communities the same. Nursing home closures may disproportionately impact certain ethnic/socio-economic areas. The identification of market and organizational contextual factors that are predictors of financial distress can complement prediction models based on financial indicators, and further assist policymakers in targeting nursing homes at risk of closure.

\section{BARRIERS AND FACILITATORS OF RETIREMENT SAVINGS FOR PRE-RETIREES IN THE UNITED STATES}

L. Sullivan, Brandeis University, Waltham, Massachusetts

The retirement landscape is undergoing significant changes in the United States as employer benefits are increasingly 